\title{
Research on Collaborative Governance Mechanism of Personal Information Security Chaos
}

\author{
Xu Wei, Wei Rong \\ Department of Information Technology, Hubei University of Police, Hubei Cooperative \\ Innovation Center for Electronic Data Forensics, Wuhan, Hubei, China, 430034
}

Keywords: personal information; collaborative governance mechanism; chaos

\begin{abstract}
With the widespread use of Internet technology and the acceleration of the informationization process, citizens' personal information has become more open and transparent, and more and more social cases have resulted from the leakage of personal information. This paper summarizes the performance of personal information security chaos in China, analyzes the harm, and combs the status of relevant protection work that has been initially carried out, and then analyzes the reasons for the poor management of personal information security chaos, and finally puts forward relevant suggestions to protect the personal information security of citizens.
\end{abstract}

\section{Introduction}

As a product of the development of information technology, personal information has become an important asset for the contemporary society. It has been taken seriously by more and more people, and it already has the nature of modern commodities [1]. Personal information, as an extremely important emerging social resource, has spread through the Internet and has become a target for individuals, businesses, and other social groups to compete for collection. This has led to the emergence of chaos in the infringement of personal information security. In recent years, social cases resulting from the disclosure of citizens' personal information have emerged in an endless stream and in various forms. They have become more intense and harmful. Therefore, in view of this chaos, it is necessary to take collaborative governance theory as a starting point to conduct a thorough and comprehensive research and discussion on the collaborative governance mechanism of personal information security protection. In addition, collaborative governance of personal information security chaos refers to organizations or individuals who have interests in the issue, and rely on their own advantages to cooperate, compete, and work to build a complete governance system, as showed in following figure 1.

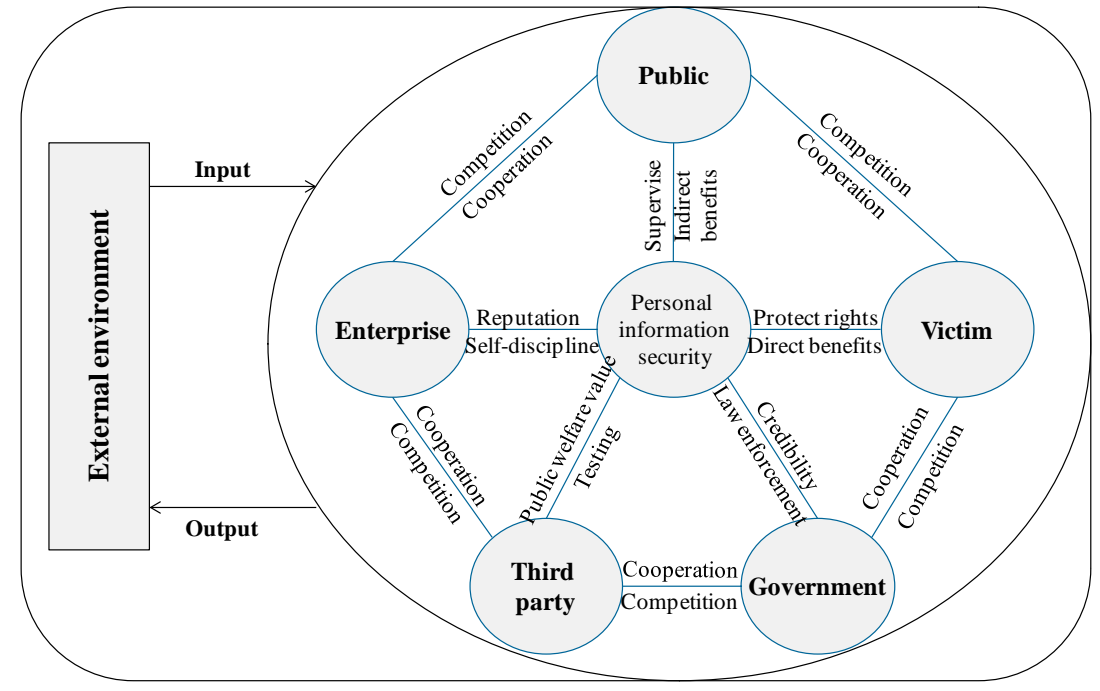

Fig.1 Personal Information Security Collaborative Governance Model 


\section{The Chaos of Personal Information Security and Governance Status}

\subsection{Illegal or improper collection of personal information}

Although the collection and collation of personal information of citizens is part of the administrative act of the government, the importance of this act should be carried out strictly in accordance with the legal procedures for the collection and use of personal information of the citizens, and no department or individual shall be allowed to cross the authority or to collect and use citizen information without approval [2]. However, in the actual work, some departments and individuals often do not handle the work in accordance with the law, resulting in a bad influence on the credibility and prestige of the law. On the one hand, the legal system for collecting personal information in China is incomplete at present stage; on the other hand, some administrative agencies have disregarded the existing laws and regulations for the convenience of their work or for other purposes.

\subsection{Illegal or improper use of personal information}

At present, the problem of illegal use of personal information is very serious. Especially with the continuous development of the Internet, personal information security is more vulnerable to violations. Such as unlawful stealing or dissemination of personal information for profit, malicious dissemination of personal information without the consent of the parties, and the sale of personal information for the purpose of profit, on the one hand, it indicates that the phenomenon of illegal use of citizen information has been in common, on the other hand, it also reflects the urgency of protecting citizen information.

\subsection{Legal mechanism initially established for the protection of personal information}

By analyzing the existing legal provisions in China at the present stage, it can be found that there is currently no special law for the protection of personal information security. However, in some relevant laws, there are provisions for this. For example, the protection of personal information is clearly stipulated in the Constitution. Personal dignity is a part of personal information and defines the inviolability of human dignity. In the criminal law, the crime of infringing on citizens' information was stipulated. In civil law, it has been determined that the right to the names, reputations and portraits of our citizens is inviolable. If they are violated, they can use legal weapons to defend their rights.

\section{Reasons for the Poor Management of Personal Information Security Chaos}

\subsection{Lack of a legal system for the protection of personal information}

At present, China's protection of citizens' personal information is mainly from two aspects, direct and indirect protection. The way of direct protection is still lacking in relevant laws and regulations. Although various laws and regulations have explicit provisions on the protection of personal information, these provisions do not appear to be sufficiently structured. They lack connectivity in the system, are fragmented in content, and are vague, especially on the protection of personal information. In many cases, only a single sentence has been passed, and the basic protection principles, protection reasons, and individual rights and other basic content are all seriously missing, and most laws and regulations do not explicitly government these contents. Therefore, in practice, many times it will be subject to subjective influence, which is very unfavorable to the solemnity of the law.

\subsection{Imperfect supervision system}

From the regulatory system to the current analysis of the administrative judiciary, we can find that the current judicial department in our country still has problems left over from the era in the long-term development. These problems are mostly caused by subjective factors, and common abuse of power and power for personal gains. At present, many incumbents of the administrative and judicial 
departments have a variety of working attitudes, such as sloppy work, lack of responsibility, etc., and judicial executives are still so, how can they guarantee the establishment and implementation of justice? Therefore, the most fundamental reason for the leakage of personal information is the lacking of regulatory system [3]. In terms of actual management measures and measures, the collection of personal information for Chinese citizens needs to be further improved. At present, China's personal information management system for citizens is still relatively lacking. Therefore, there will be incidents in which the unrelated personnel are aware of the incidents during the process of personal information transmission, which leads to the disclosure of information and brings certain risks to the public.

\subsection{Weak awareness of the protection of personal information of citizens}

In terms of legal culture, due to the long-term lack of legal system, most people's legal awareness and awareness of rights protection are obviously insufficient. Many people only know that they have due obligations and do not know that they still have the right to enjoy and exercise. Some people even think that their privacy has not been excessively violated is already a right. In the absence of public awareness of rights protection, government agencies and their civil servants will also be lax in their awareness and enforcement of civil rights protection. All sorts of disregard for personal privacy do not help to improve the protection of personal information of our citizens for a long time.

\section{The Collaborative Governance of Personal Information Security Chaos}

\subsection{Improve laws and regulations on the protection of personal information security}

First of all, it is necessary to supplement and perfect some existing legal content in China, but the prerequisite is to ensure the consistency of legal content, especially in the supervision of infringement, we should establish a sound legal content protection system. For example, the content of risk management and accountability in China's current laws is not perfect, there are many drawbacks to the specific content. In addition, in order to better apply the relevant laws of our country in the protection of information, the legislative departments should carry out legislation according to the different nature of different regions, so as to ensure that the operational nature of the law of our country is more powerful, and only in this way can we carry out better personal information security supervision and management. Secondly, it is necessary to increase penalties for violations of other people's information, and to appropriately increase compensation.

\subsection{Develop clear personal information security protection standards}

The information security protection standards are not for individuals, it is mainly used to play a role in the relevant regulators. They are the highest priority in the protection of citizen information, and important criterions that national regulator must be followed [4]. At present, although the relevant protection standards have been formulated, there are many loopholes and many aspects are not involved, which is a challenge to the reasonable development of supervision in China. Therefore, the current protection standards should be supplemented and perfected as soon as possible, and the standards of some industries and places should be unified to ensure that the supervision work has a definite reference basis.

\subsection{Clear the relevant responsibility of the regulators}

In administrative management, there are many types of responsible systems, and the most important one is the leadership responsibility system. There are two main considerations in the operation of this system. The first is to ensure that administrative departments have high administrative efficiency. The second is to ensure that when there is a big mistake, the relevant responsible objects could be found. This will force the responsible person to devote himself to the administrative work, and it is impossible to make acts that endanger the safety of personal information. 


\subsection{The construction of personal information security collaborative governance model}

At present, the management of personal information is more complex and covers a wider area. Therefore, to carry out effective protection of personal information security, it is necessary to change the existing single governance and supervision mechanisms, and establish a collaborative model of multi-sector and institutional collaboration. The following table shows the content of the collaborative governance mechanism.

Table1. Collaborative governance measures

\begin{tabular}{cl}
\hline Stakeholders & \multicolumn{1}{c}{ Governance measures } \\
\hline Government agencies & $\begin{array}{l}\text { Play the leading role, do a good job of supervision, and build a sound } \\
\text { governance system. } \\
\text { Directly participate in various activities and conduct supervision of } \\
\text { enterprises and individuals, and actively feedback real information and } \\
\text { provides constructive opinions. } \\
\text { Supervise and expose incidents that endanger the safety of citizens' } \\
\text { Citizens }\end{array}$ \\
$\begin{array}{l}\text { Sersonal information. } \\
\text { Enhance the awareness of personal information protection and the } \\
\text { enthusiasm of privacy protection. }\end{array}$ \\
\hline
\end{tabular}

\subsection{Cultivate citizens' good awareness of information security}

It is the most appropriate choice for the citizens to conduct related information security education because of the uniqueness of this educational content. In addition, we should maximize the use of media and other tools, especially forums or websites with more audience, which can ensure that the object of information security education be increased as much as possible. In the process of education, information security is not only related to individuals, but also to information security of countries and enterprises. When conducting education activities for citizens, it should start from two perspectives, namely the ability of citizens to identify dangers and their ability to protect information. Regarding the security of national information, it is necessary to provide relevant personnel with legal, technical prevention, and moral education and training, and comprehensively improve their ability to protect national information. Particular emphasis should be placed on maximizing the content of education for individuals to be extended to government officials, so as to ensure that these people have a deep understanding of information protection, and to comprehensively improve the level of information protection in China.

\section{Summary}

With the development of society, the value of information resources has become increasingly prominent, which has led to more frequent of personal information security violations. In this context, government agencies, social organizations, and the public must cooperate closely to jointly promote the resolution of issues. On the one hand, the government should clarify and improve the relevant laws on the protection of personal information security, so that citizens can protect their personal information security. On the other hand, it is necessary to improve the relevant management mechanism and clarify the main body of supervision. With the help of the collaborative governance, a sound collaborative governance mechanism should be established to guide the entry of social organizations and the general public, and to improve management efficiency. Finally, at the individual level, everyone should establish a sense of information security protection and prevent their information from being leaked.

\section{References}

[1] Cai Wentong. Research on Personal Information Protection in the Internet Age[J]. Wireless Internet Technology,2015(15), p.25

[2] He Siqi. Analysis of the Status Quo and Causes of the Protection of Personal Information of 
Chinese Citizens[J]. Law Exposition, 2016(33), p.43

[3] Qian Li, Tan Jinke. Consummation of the Internet Privacy Protection Legislation in the "Internet Plus” Age[J]. China Circulation Economy, 2017(12), p.51

[4] Yan Xiaoli. Study on Personal Information and Privacy Protection Legislation in the Era of Big Data[J]. Secret Science and Technology,2015(09). p.29 